\title{
Degenerative Lumbar Spinal Stenosis: Diagnosis and Management
}

\section{Ahmed Saleh*, Ramin Sadeghpour and Kevin K Kang}

Department of Orthopaedic Surgery, Maimonides Medical Center, Brooklyn, New York, USA

\begin{abstract}
Lumbar Spinal Stenosis (LSS) is one of the most common spinal pathologies in the United States. LSS is a degenerative spine disorder that affects primarily people over the age of 50 and is one of the most common sine diagnoses requiring surgical intervention in this age group. This article aims to summarize the presentation, examination, work up, and management of the patient with LSS as well as touch upon some the latest clinical trials to aid in the practice of evidence based medicine.
\end{abstract}

Keywords: Lumbar Spinal Stenosis; Lumbar stenosis; Spinal stenosis

\section{Introduction}

Lumbar Spinal Stenosis (LSS) is one of the most common spinal pathologies in the United States. LSS is characterized by narrowing of the spinal canal creating compression of the neural structures causing a constellation of symptoms that may include low back pain, lower extremity radiculopathy, neurogenic claudication, and gait impairment. The rates of spinal stenosis continues to increase significantly as the population of the US ages and the average life span increases [1,3]. As the number of old age people continue to grow in the United States, it can be expected that the prevalence of LSS will also increase.

Spinal Stenosis is generally classified as either congenital or acquired. Congenital spinal stenosis is found in individuals who have short pedicles, which decreases the area of the spinal canal. This is very common in individuals with achondroplasia, but may also occur in people of normal stature [2]. Acquired spinal stenosis is much more common and is caused by central and lateral canal stenosis secondary to spinal degeneration. This stenosis is caused by facet and ligamentum flavum hypertrophy, foraminal stenosis, disc herniation, and osteophyte formation $[2,3]$.

\section{Symptoms and Physical Exam}

Patients with LSS most commonly present with low back pain and neurogenic claudication. As in all spinal pathologies, a thorough history regarding the patient's symptoms is indicated. Symptoms of LSS usually have a very insidious onset and progress slowly [4]. Symptoms may be either unilateral or bilateral. Patients often complain of pain in the back, buttocks, thighs, calves, and feet when walking. This pain is often exacerbated when walking longer distances. Generally, the pain experienced is relieved at rest. Classically, these symptoms are exacerbated when the spine is in extension, such as walking down a hill, but relieved while the spine is flexed such as leaning forward on a cart. This constellation of symptoms is defined as, neurogenic claudication [5]. Extension of the spine decreases the volume of the spinal canal exacerbating the symptoms, while flexion increases the volume of the spinal canal relieving symptoms. Gait abnormalities and bladder and bowel disturbances should also be assessed for in these patients.

Systematic reviews, looking at the diagnostic accuracy of clinical tests in patients with lumbar spinal stenosis revealed that the symptoms of radiating leg pain and thigh pain when standing up had the highest sensitivity for LSS. Also, the absence of symptoms when seated, or the improvement of symptoms with forward bending, as well as wide based gait were useful for ruling in LSS [6,7].

A thorough spine exam should be performed in all patients with suspected LSS. The exam should begin with the inspection of the overall spinal alignment. Tenderness to palpation of the lumbosacral spine can sometimes be present. Range of motion of the spine should be noted, and decreased lumbar motion is not uncommon. Range of motion of the hips and knees to assess for degenerative arthritis should also be performed. Provocative tests such as straight leg raises may help differentiate symptoms of stenosis with that of a disc herniation. One should also assess for lower extremity muscle strength, which may be reduced in patients with LSS. Sensation for light touch and vibratory sense should be assessed. Reflexes should also be assessed. Gait pattern and Romberg test should be considered as part of a complete physical examination in these patients. In patients with abnormal gait patterns, cervical myelopathy should also be considered $[4,6]$

The differential diagnosis of LSS is broad. One should rule out other common causes of lower extremity symptoms. Degenerative osteoarthritis of the hip or knee can cause similar lower extremity symptoms, and should be explored. Vascular claudication can also present similarly to neurogenic claudication, so peripheral vascular disease should be ruled out as a potential cause of lower extremity pain [8]. A thorough vascular examination should be performed. In patients with atypical claudication ankle-brachial index may be useful as a screening test to determine whether the origin is vascular in nature [9]. Neurologic disorders such as diabetes with peripheral neuropathy, or a peripheral compressive neuropathy may also present with similar symptoms, and their diagnosis should be ruled out as a potential cause of the patient's symptoms [4].

\section{Imaging and Diagnostic Examinations}

Imaging is often necessary in patients with LSS to determine the exact level of stenosis and to determine the severity of the stenosis The current mainstay of spinal imaging for Lumbar Spinal Stenosis is magnetic resonance imaging (MRI). MRI can identify nerve compression and can also be used to determine the cross-sectional area of the spinal canal. In a patient where surgical intervention is being considered, MRI can be very useful in the determination of the spinal levels requiring decompression, and other anatomic considerations $[4,8]$. Studies have shown that the inter-reader reliability of central canal stenosis, soft tissue canal area, and thecal sac area was substantial

*Corresponding author: Ahmed Saleh, Department of Orthopedics Surgery, Maimonides Medical Center, Brooklyn, New York, USA, Fax: 718-283-6199; E-mail: asaleh@maimonidesmed.org

Received June 10, 2013; Accepted July 31, 2013; Published August 03, 2013

Citation: Saleh A, Sadeghpour R, Kang KK (2013) Degenerative Lumbar Spinal Stenosis: Diagnosis and Management. J Spine S2: 005. doi:10.4172/2165-7939. S2-005

Copyright: $\odot 2013$ Saleh A, et al. This is an open-access article distributed under the terms of the Creative Commons Attribution License, which permits unrestricted use, distribution, and reproduction in any medium, provided the original author and source are credited. 
[10]. Patients who cannot undergo an MRI, such as patients with pacemakers, a CT myelogram can be considered.

Studies are split when looking at the correlation between the cross sectional area of the spinal canal and the patients symptoms. Some studies suggest that the cross sectional area of the spinal canal may be a predictor of a patients preoperative walking ability, back and leg pain, and directly relates the quality of life of patients with central stenosis [11]. Other studies looking the patients walking ability when compared to their cross sectional area revealed a very poor correlation $[12,13]$. The North American Spine Society (NASS) Evidence based clinical guidelines for Degenerative Lumbar Spinal Stenosis deems the data is insufficient to make a proper determination [14].

The provider however must be certain to use the MRI as an adjunct to a thorough history and physical exam, as LSS is primarily a clinical and not a radiographic diagnosis. Many studies revealed that even asymptomatic patients may have abnormal MRI or CT scans $[15,16]$. It can be difficult to determine the exact cause of a patient's pain. With the differential of lumbar spinal stenosis being so broad, including hip osteoarthritis, vascular pathology, facet joint pain, sacroiliac pain, and even neuropathies, it is very important for the provider to be certain that the patient's pain is indeed a due to lumbar stenosis. Even with a thorough history, the etiology of the patient's pain may still be unclear. A study looking at patients with both evidence of LSS and hip osteoarthritis revealed that the pain of some people persisted even after decompression spine surgery, but resolved with total hip arthroplasty [17]. This shows that even sometimes with a thorough history, physical exam and imaging, an exact cause of the patient's pain can still be elusive.

Recent evidence reveals that another diagnostic modality that can help in the diagnosis of LSS is electromyography. Studies show that in elderly patients electromyography is superior to MRI in determining which patients were symptomatic or asymptomatic $[18,19]$. Electromyography has been shown to have a high specificity in the diagnosis of LSS [20].

Standard lumbar spine AP and Lateral X-rays may be helpful in determining the extent of degeneration of the spine. Findings such as disc space narrowing, facet joint hypertrophy, and osteophyte formation should be noted [8]. X-rays can also help to rule out other pathologic conditions such as tumors or fractures. Spondylolisthesis should also be noted. Dynamic flexion and extension views should be obtained which will help to determine if there is any evidence of spinal instability causing the symptoms [4].

\section{Nonoperative Management}

Treatment of lumbar spinal stenosis is generally a multimodal approach that may culminate in surgical intervention if symptoms cannot be controlled with nonoperative methods. Although there is no great evidence, NSAID medication is often recommended as a first line attempt to control the symptoms of LSS [21].Stronger analgesics such as narcotic medications can be used for a very short period of time but are not recommended for chronic pain control as they have no effect on the natural history of the disorder [22]. Steroids and muscle relaxants may also be used but generally only work for short term symptom relief [4]. Gastrointestinal upset and bleeding is a side effect that the provider should warn the patient about.

As in most musculoskeletal diagnoses, a multidisciplinary approach is often used in the treatment of spinal stenosis. A thorough assessment of the patient's symptoms, baseline functional status, and the patient's goals of treatment should be taken into consideration when directing a treatment plan. Since the spectrum of the LSS is quite broad varying from occasional pain and neurogenic claudication to severe disability and bowel and bladder dysfunction, a multimodal approach if often necessary help the patient achieve their goals of treatment. Physical therapy and occupational therapy is often used to help the patient either return to their baseline functional status, or to help them complete their activities of daily living in safe and effective manner. Both of these providers also have the ability to recommend possible assistive devices such as walkers, wheelchairs, or scooters to help increase mobility.

In patients who are not surgical candidates, the focus of treatment turns to symptom control. Pain management specialists can help patients control their pain. Physiatrists and occupational therapists can help the patient to maintain mobility, and even urologists can be utilized to help the patient to deal with potential bladder dysfunction.

Physical therapy is also an often used and prescribed treatment modality in patients with LSS. Although once again there is very little scientific evidence that a course of physical therapy can help with the overall treatment of spinal stenosis, it is advocated the patients receive a nonoperative trial of both NSAID medication and physical therapy prior to consideration for surgery [12]. There are many different treatment modalities for physical therapy. Classically, for patients with LSS, flexion type exercises has been advocated for symptom relief. A recent study has shown that manual physical therapy may be more effective than flexion type exercises in the treatment of LSS [23].

Epidural steroid injections have also been used to treat patients with LSS. An injection of a steroid mixed with a local anesthetic is used and is injected locally into the affected area. Although the actual mechanism of their action is poorly understood, it is thought that the local anti-inflammatory effect decreases symptoms [24]. Studies have shown that epidural steroid injections can be beneficial to patients when combined with NSAIDs and a home exercise program [14].

\section{Operative Management}

Operative treatment is reserved for patients who have failed the nonoperative management of LSS and are good surgical candidates. A good surgical candidate is a patient in which after a thorough history, physical, and workup demonstrates that his pain is indeed secondary to spinal stenosis and other causes of pain and claudication have been ruled out. Patients with multiple medical comorbidities which may be very high risk for surgery should be treated nonoperatively if possible.

Prior to surgical intervention, the surgeon must determine which, what type of surgery would be the most beneficial for the surgical candidate. For LSS with no evidence of instability, a lumbar decompression surgery via a laminectomy with no fusion is indicated. A laminectomy is performed to decompress the neural elements, but care must be taken to preserve the majority of the facet joint or iatrogenic spinal instability may occur [4]. If there is involved nerve root compression, a foraminotomy may also be indicated [25]. In patients who exhibit spinal instability in dynamic flexion and extension views, or those who have evidence of spondylolisthesis, decompression along with fusion is often indicated $[4,8]$. There is however increasing evidence that the rate of decompression and fusion is increasing when compared to that of sole decompression in the treatment of LSS [26]. There have been many studies looking at the effectiveness of just decompression surgery versus decompression and fusion. There is still no absolute consensus in the literature, but a systematic review article performed by Resnick et al. in 2005 in the Journal of Neurosurgery recommended that in patients with pure lower extremity symptoms with no evidence of spondylolisthesis only decompression should be performed [27]. He also recommended that in patients with LSS and 
spondylolisthesis a decompression and fusion should be performed [28]. The NASS surgical guidelines recommended decompression alone for patients with predominantly lower extremity symptoms [14].

There have been several studies exploring the effectiveness of decompressive surgery in the treatment of LSS. The results of these studies vary tremendously and standardization has historically been poor due to lack of a standardized outcome measure. Many studies use functional and pain score testing to determine the effectiveness of surgical intervention, while others use exercise testing such as the bicycle or treadmill tests [29]. A study performed at the Brigham and Women's Hospital revealed a $15 \%$ reoperation rate, with $30 \%$ of the study population still experiencing severe pain after surgery with a minimum of 2.8 years of follow up [30]. In another study out of Schulthess Hospital in Zurich, they randomized patients with LSS into 3 groups viz., decompressive laminectomy, decompressive laminectomy with one level fusion, and decompressive laminectomy with multilevel fusion. This study revealed that after 28 months of follow up, the 3 groups had similar pain and functional outcomes. They concluded that arthrodesis was not necessary after decompressive laminectomy in patients with no evidence of spinal instability [31].

One of the landmark in spine surgery was randomized control trials, The Spine Patient Outcomes Research Trial (SPORT) demonstrated the superiority of surgical treatment of LSS when compared to nonoperative management. In this randomized study, 289 patients were randomized into a surgical or nonsurgical group. Although there was significant crossover in each of the groups, analysis showed that the patients who had undergone surgical decompression for LSS had significantly better outcomes than those treated nonoperatively. The outcome measures that were analyzed in this study were several pain and functional outcome scores. There was minimum of two years of follow up in this study [32]. In a four year follow up study involving the SPORT trial participants, the significance of continued improvement in pain and functional outcomes was still maintained [33]. Systematic reviews looking at all the randomized trials for LSS have also determined the superiority of surgery over conservative treatment [34].

With the advent of the thought of developing newer muscle and bone sparing approaches, several new techniques were developed to treat LSS. Procedures such as the laminotomy, microedoscopic laminotomy, laminoplasty, and foraminotomy have been shown to be effective in the treatment of LSS [35]. In a laminoplasty, the posterior elements are expanded, usually via a bone block technique effectively expanding the volume of the spinal canal and relieving the symptoms of LSS. With this amount of bone preservation, iatrogenic instability is less likely to occur [36]. Even newer techniques, such as the iO-Flex system, are minimally invasive and use a flexible microblade to help decompress the neuroforamina [23].

Another new technique for the treatment of LSS is the X-Stop implant. The X-Stop implant is an interspinous distraction device that reduces pathologic extension at the symptomatic levels, hence decreasing the symptoms of LSS. A randomized multicenter study looking at 100 patients treated with the X-Stop device versus 91 patients treated conservatively revealed that a significant improvement in pain and functional scores those treated with the X-Stop when compared to the control group. This study also showed higher patient satisfaction scores in the X-Stop group [37]. A recent randomized study looking at 100 patients who were randomized to either decompressive laminectomy or the X-Stop implant revealed similar pain and functional outcome scores at 2 years follow up. However, the $\mathrm{X}$-Stop group had $26 \%$ reoperation rate when compared to only $6 \%$ in the decompression group [38].
Although the treatment for LSS has been straightforward decompression for many years, newer techniques and advances in the field of spine surgery have revealed several new, advanced, and minimally invasive techniques. The level of evidence of the effectiveness of these techniques however, is yet to be determined.

\section{References}

1. Kalichman L, Cole R, Kim DH, Li L, Suri P et al. (2009) Spinal Stenosis Prevalence and Association with Symptoms: The Framingham Study. Spine J 9: 545-550.

2. Garafin SR, Herkowitz HN, Mirkovic S (1999) Instructional Course Lectures The American Academy of Orthopaedic Surgeons - Spinal Stenosis. J Bone Joint Surg Am 81: 572-586.

3. Spivak JM (1998) Current Concepts Review: Degenerative Lumbar Spinal Stenosis. J Bone Joint Surg Am 80: 1053-1066.

4. Hilibrand AS, Rand N (1999) Degenerative Lumbar Stenosis: Diagnosis and Management. J Am Acad Orthop Surg 7: 239-249.

5. Porter RW (1996) Spinal Stenosis and Neurogenic Claudication. Spine 21 2046-2052.

6. de Graaf I, Prak A, Bierma-Zeinstra S, Thomas S, Peul W, et al. (2006) Diagnosis of Lumbar Spinal Stenosis: A Systematic Review of the Accuracy of Diagnostic Tests. Spine 31: 1168-1176.

7. De Shepper EIT, Overdevest GM, Suri P, Peul WC, Oei EH, et al. (2013) Diagnosis of Lumbar Spinal Stenosis: An Updated Systematic Review of the Accuracy of Diagnostic Tests. Spine 38: E469-E481.

8. Issack PS, Cunningham ME, Pumberger M, Hughes AP, Cammisa FP Jr (2012) Degenerative Lumbar Spinal Stenosis: Evaluation and Management. J Am Acad Orthop Surg 20: 527-535.

9. Jeon $\mathrm{CH}$, Han $\mathrm{SH}$, Chung NS, Hyun HS (2012) The Validity of ankle-brachia index for the differential diagnosis of peripheral arterial disease and lumbar spinal stenosis in patients with atypical claudication. Eur Spine J 21: 11651170.

10. Lurie JD, Tosteson AN, Tosteson TD, Carragee E, Carrino JA, et al. (2008) Reliability of Readings of Magnetice Resonance Imaging Features of Lumbar Spinal Stenosis. Spine 33: 1605-1610.

11. Ogikubo O, Forsberg L, Hansson T (2007) The Relationship Between the Cross-sectional Area of Cauda Equina and Preoperative Symptoms in Central Lumbar Spinal Stenosis. Spine 32: 1423-1428.

12. Zeifang F, Schiltenwolf M, Abel R, Moradi B (2008) Gait analysis does not correlate with clinical and MR imaging parameters in patients with symptomatic lumbar spinal stenosis. BMC Musculoskelet Disord 9: 89.

13. Sirvanci M, Bhatia M, Ganiyusufoglu KA, Duran C, Tezer M, et al. (2008) Degenerative Lumbar Spinal Stenosis: Correlation with Oswestry Disability Index and MR imaging. Eur Spine J 17: 679-685

14. Kreiner DS, Shaffer WO, Baisden JL, Gilbert TJ, Summers JT, et al. (2013) An evidence-based clinical guideline for the diagnosis and treatment of degenerative lumbar spinal stenosis (update). Spine J 13: 734-743.

15. Boden SD , Davis DO , Dina TS, Patronas NJ, Wiesel SW (1990) Abnorma magnetic-resonance scans of the lumbar spine in asymptomatic subjects. A prospective investigation. J Bone Joint Surg Am 72: 403-408.

16. Wiesel SW, Tsourmas N, Feffer HL, Citrin CM, Patronas N (1984) A study of computer assisted tomography. I. The incidence of positive CAT scans in an asymptomatic group of patients. Spine 9: 549-551.

17. Saito J, Ohtori S, Kishida S, Nakamura J, Takeshita M, et al. (2010) Difficulty of Diagnosing the Origin of Lower Leg Pain in Patients with Both Lumbar Spina Stenosis and Hip Joint Osteoarthritis. Spine 37: 2089-2093.

18. Haig AJ, Geisser ME, Tong HC, Yamakawa KS, Quint DJ, et al. (2007) Electromyographic and magnetic resonance imaging to predict lumbar stenosis, low-back pain, and no back symptoms. J Bone Joint Surg Am 89: 358 - 366.

19. Haig AJ, Tong HC, Yamakawa KS, Quint DJ, Hoff JT, et al. (2006) Spinal stenosis, back pain, or no symptoms at all? A masked study comparing radiologic and electrodiagnostic diagnoses to the clinical impression. Arch Phys Med Rehabil 87: 897 - 903.

20. Haig AJ, Tong HC, Yamakawa KS, Quint DJ, Hoff JT, et al. (2005) The sensitivity and specificity of electrodiagnostic testing for the clinical syndrome of lumbarspinal stenosis. Spine 30: 2667 - 2676. 
Citation: Saleh A, Sadeghpour R, Kang KK (2013) Degenerative Lumbar Spinal Stenosis: Diagnosis and Management. J Spine S2: 005. doi:10.4172/2165-7939.S2-005

21. Ammendolia C, Stuber K, de Bruin LK, Furlan AD, Kennedy CA, et al (2012) Nonoperative Treatment of Lumbar Spinal Stenosis with Neurogenic Claudication: A Systematic Review. Spine 37: E609-E616.

22. Brodke DS, Ritter SM (2005) Nonoperative Management of Low Back Pain and Lumbar Disc Degeneration. Instr Course Lect 54: 279-86.

23. Whitman JM, Flynn TW, Childs JD, Wainner RS, Gill HE, et al. (2006) A Comparison Between Two Physical Therapy Treatment Programs for Patients with Lumbar Spinal Stenosis: A Randomized Clinical Trial. Spine 31: 25412549.

24. Koc Z, Ozcakir S, Sivrioglu K, Gurbet A, Kucukoglu S. et al. (2009) Effectiveness of Physical Therapy and Epidural Steroid Injections in Lumbar Spinal Stenosis. Spine 34: 985-989

25. Cirak B, Alptekin M, Palaoglu S, Ozcan OE, Ozgen T (2001) Surgical Therapy for Lumbar Spinal Stenosis: Evaluation of 300 Cases. Neurosurg Rev 24: 8082.

26. Bae HW, Rajaee SS, Kanim LE (2013) Nationwide Trends in the Surgical Management of Lumbar Spinal Stenosis. Spine 38: 916-926.

27. Resnick DK, Choudhri TF, Dailey AT, Groff MW, Khoo L, et al. (2005) Guidelines for the performance of fusion procedures for degenerative disease of the lumbar spine. Part 10: Fusion following decompression in patients with stenosis without spondylolisthesis. J Neurosurg Spine 2: 686-691.

28. Resnick DK, Choudhri TF, Dailey AT, Groff MW, Khoo L, et al. (2005) Guidelines for the performance of fusion procedures for degenerative disease of the lumbar spine. Part 9: Fusion in patients with stenosis and spondylolisthesis. J Neurosurg 2: 679-685.

29. Yukawa Y, Lenke LG, Tenhula J, Bridwell KH, Riew KD, et al. (2002) A Comprehensive Study of Patients with Surgically Treated Lumbar Spina Stenosis with Neurogenic Claudication. J Bone Joint Surg Am 84: 1954-1959.
30. Katz JN, Stephen LJ, Larson MG, Mclnnes JM, Fossel AH (1991) The Outcome of Decompressive Laminectomy for Degenerative Lumbar Stenosis. J Bone Joint Surg Am 73: 809-816.

31. Grob D, Humke T, Dvorak J (1995) Degenerative Lumbar Spinal Stenosis Decompression With and Without Arthrodesis. J Bone Joint Surg Am 77: 10361041.

32. Weinstein JN, Tosteson TD, Lurie JD, Tosteson AN, Blood E, et al. (2008) Surgical versus Nonsurgical Therapy for Lumbar Spinal Stenosis. N Engl J Med 358: 794-810.

33. Weinstein JN, Tosteson TD, Lurie JD, Tosteson A, Emily Blood E, et al. (2010) Surgical versus Nonsurgical Treatment for Lumbar Spinal Stenosis Four-Year Results of the Spine Patient Outcomes Research Trial. Spine 35: 1329-1338.

34. Kovacs FM, Urrutia G, Alarcon JD (2011) Surgery Versus Conservative Treatment for Symptomatic Lumbar Spinal Stenosis: A Systematic Review of Randomized Controlled Trials. Spine 36: E1335-E1351.

35. Lauryssen C (2010) Technical Advances in Minimally Invasive Surgery: Direct Decompression for Lumbar Spinal Stenosis. Spine 35: S287-S293.

36. Kawaguchi $\mathrm{Y}$, Kanamori M, Ishihara H, , Kikkawa T, Matsui H, et al. (2005) Clinical and Radiographic Results of Expansive Lumbar Laminoplasty in Patients with Spinal Stenosis: Surgical Technique. J Bone Joint Surg Am 87: 292-299.

37. Zucherman JF, Hsu KY, Hartjen CA, Mehalic TF, Implicito DA, et al. (2005) A Multicenter, Prospective, Randomized Trial Evaluating the X STOP Interspinous Process Decompression System for the Treatment of Neurogenic Intermittent Claudiation: Two-Year Follow-Up Results. Spine 30: 1351-1358.

38. Stromqvist BH, Berg S, Gerdhem P, Johnsson R, Moller A, et al. (2013) X-Stop Versus Decompressive Surgery for Lumbar Neurogenic Intermittent Claudication: A Randomized Controlled Trial with 2 Years Follow-up. Spine. 38: $1436-42$ 